\title{
Daily Prediction of Electricity Rates of Distribution Utilities in Luzon
}

\author{
Jackie D. Urrutia ${ }^{1 *}$, Nathan C. Resurreccion ${ }^{1}$, Leah Mariel C. Visco' \\ Lincoln A. Bautista', Rolan J. Malvar', Audie B. Oliquino' and Leila A. Gano ${ }^{2}$
}

'Polytechnic University of the Philippines - Sta. Mesa, Manila, Philippines; jdurrutia@pup.edu.ph, jackieurrutia20@ gmail.com,math_urrutia@yahoo.com.ph,rjmalvar@pup.edu.ph,rjmalvar@gmail.com, aboliquino@pup.edu.ph, labautista@pup.edu.ph, visco.leahmariel@gmail.com, nathan.ts08@gmail.com ${ }^{2}$ Philippine College of Health and Science - Claro M. Recto Avenue, Manila, Philippines; gano.leila@yahoo.com

\begin{abstract}
Objectives: The main objective of this study is to develop a best model that will forecast the electricity rates of distribution utilities in Luzon. Methods/Statistical Analysis: The secondary data of price, demand and supply of electricity of distribution utilities per region in Luzon from January 2015 to March 2017 that was used in the study were gathered from MERALCO that were obtained from the official website of Wholesale Electricity Spot Market (WESM). The data were analysed by the use of statistical software such as EViews7 and MATLAB. Findings: The data were analyzed by the use of statistical software such as EViews7 and MATLAB. The models used for forecasting the participants' electric demand is ARIMA $(1,1,1)$ for CAR, Region 1, Region 2, Region 3, Region 4B and Region 5. The models for forecasting the supply of electricity are: ARIMA $(2,1,2)$ for CAR, ARIMA $(3,1,1)$ for NCR and Region 1 , ARIMA $(3,1,2)$ for Region 2 , ARIMA $(1,1,1)$ for Region 3 and ARIMA $(2,1,1)$ for Region 4A and Region 5 . The forecasted demand of electricity of distribution utilities in every region for years 2017-2019 will continue to increase. The forecasted electric supply of distribution utilities in every region for years 2017-2019 will go through an increase and decrease from time to time but still trending upwards. Additionally, it was also shown that there were no significant differences between the actual and forecasted values. Application/Improvements: Using the model electricity demand and supply rates of distribution utilities in Luzon were forecasted for the next two years.
\end{abstract}

Keywords: ARIMA Modeling, Demand and Supply, Electricity Rates, Forecasting, Luzon

\section{Introduction}

Electricity is one of the most important goods for our society. Forecasting electricity prices at different time frames is very important for all industry stakeholders for cash flow analysis, capital budgeting and financial procurement as well as regulatory rule-making and integrated resource planning, among others ${ }^{1}$.

The most important outcome of an electricity market is the formation of a price at which all power is traded, at least on a daily basis, by way of the so-called SPOT mar- ket. The daily (spot) electricity markets serves as a marketplace of last resort for generator and demands to trade their remaining available not-contracted power.

The Wholesale Electricity Spot Market (WESM) provided a platform that allowed the sale and purchase of electricity supplies every day for every given hour ${ }^{2}$. The WESM matches bids and offers, enabling electricity supply and demand to be met at any given hour.

Based on the needs of the energy market, a variety of approaches for electricity price, supply and demand forecasting have been proposed in the last decades, among 
them, models based on simulation of power system equipment and related cost information ${ }^{3}$ game-theory based models which focus on the impact of bidder strategic behavior on electricity prices ${ }^{4}$, models based on stochastic modeling of finance ${ }^{5}$, regression models ${ }^{6}$ and artificial intelligence models ${ }^{7}$.

This research aims to determine an appropriate ARIMA model used to forecast the daily electric demand and supply of distribution utilities per region in Luzon. Specifically, this study sought an answer for the following questions:

- What has been the behaviour of the electricity in Luzon, based on the daily demand and supply of distribution utilities per region for January 2015 to March 2017?

- What is the most appropriate model for forecasting the electricity rates of distribution utilities per region in Luzon for years 2017 to 2019?

- What is the forecasted value of daily electric demand and supply of distribution utilities per region in Luzon?

- Is there a significant difference between the actual value and forecasted value?

\section{Methods}

This section presents the methods used by the researchers in conducting the study. It includes the statistical treatments applied in order to come up with the expected outputs.

Box-Jenkins Methodology is technically known as the ARIMA methodology. This forecasting procedure was developed by two statisticians, George Edward Peiham and Gwilyn Merion Jenkins. This methodology involves the following stages (Gujarati, 2008):

- Identification - Assess whether the time series is stationary and if not, how many differences are required to make it stationary. Identify the parameters of the ARMA model.

- Estimation - Estimation involves using numerical methods to minimize a loss or error term. After the appropriate $\mathrm{p}$ and $\mathrm{q}$ values were identified, the parameters of autoregressive and moving average terms included in the model were estimated using EViews7 through least squares.
- Diagnostic Checking - The idea of diagnostic checking is to look for evidence that the model is not a good fit for the data. To determine if the estimated model is statistically adequate, the residuals of the chosen model were tested if they are white noise. White noise residuals are characterized by: Zero mean and constant variance; (normally distributed; and independent.

A test of stationarity (or non-stationarity) that has become widely popular over the past several years is the unit root test. The researchers used Augmented DickeyFuller test statistics. The Augmented Dickey-Fuller test is an improved Dickey-Fuller test, derived from the regression model.

Augmented-Dickey Fuller (2013) test is used to determine whether a unit root, a feature that can cause issues in statistical inference, is present in an autoregressive model. It is the simplest approach to test for a unit root. Given an observed time series $Y_{1}, Y_{2} \ldots$ Yn, Dickey and Fuller consider a differential-form autoregressive equation to detect the presence of a unit root:

$$
\Delta Y_{t}=\alpha+\beta t+\gamma Y_{t-1}+\sum_{j=1}^{p}\left(\delta_{j} \Delta Y_{t-j}\right)+e_{t}
$$

$t$ is the time index, $\alpha$ is an intercept constant, $\beta$ is the coefficient on a time trend, $\gamma$ is the coefficient presenting process root, $p$ is the lag order of the first-differences autoregressive process and $e_{\mathrm{t}}$ is an independent identically distributes residual term.

Correlogram is also called as Autocorrelation Function or Serial Correlation Function. It is a graph, at the same time, a statistical procedure for the analysis of time series data and to test for the presence of cyclic phenomena ( $\mathrm{Li}, 2012)$. ACF is written as:

$$
r_{k}=\frac{\sum_{t=1}^{n-k}\left(y_{t}-\bar{y}\right)\left(y_{t+k}-\bar{y}\right)}{\sum_{t=1}^{n}\left(y_{t}-\bar{y}\right)^{2}}
$$

Where $r_{\mathrm{k}}$ is the autocorrelation coefficient, $t$ is the observations, and $\bar{y}$ is the mean.

For time series $x(t), t=0,1,2, \ldots$ the auto-covariance at lag $k$ is defined as:

$$
y_{k}=\operatorname{Cov}\left(x_{t}, x_{t+k}\right)=E\left(x_{t}-\mu\right)\left(x_{t+k}+\mu\right.
$$


The autocorrelation coefficient at lag $\mathrm{k}$ is defined as:

$$
\rho_{k}=\frac{y_{k}}{y_{0}}
$$

Since both covariance and variance are measured in the same units of measurement, is a unit less or pure number. It lies between -1 and +1 , as any correlation coefficient does. The partial autocorrelation function PACF is used to measure in the correlation between an observation $\mathrm{k}$ period ago and the current observation, after controlling for observations at intermediate lags.

The ARIMA procedure analyzes and forecasts equally spaced univariate time series data, transfer function data and intervention data using the Autoregressive Integrated Moving-Average (ARIMA). An ARIMA model predicts a value in a response time series as a linear combination of its own past values, past errors and current and past values of other time series. In terms of $y$, the general forecasting equation is:

$$
\hat{y}_{t}=\mu+\phi_{1} y_{t-1}-\theta_{1} e_{t-1}
$$

Where $\hat{y}$ is the forecasted values of the dependent variable, $t$ is the time index, $\mu$ is the intercept, $\phi$ is the Autoregressive (AR) operator and $\theta$ is the Moving Average (MA) operator (Nau, 2015).

A paired t-test (2004) is used to compare two population means where you have two samples in which observations in one sample can be paired with observations in the other sample. It is written as:

$$
t=\frac{\bar{y}-\mu}{\frac{\sigma}{\sqrt{n}}}
$$

Where $\bar{y}$ is the mean, $\mu$ is the hypothesized difference, $\sigma$ is the standard deviation, and $n$ is the sample size.

\section{Results and Discussions}

This chapter presents the descriptive analysis for the daily electric demand and supply of distribution utilities per region in Luzon from January 2015 - March 2017. Using this data, a forecasting model for each region was built using ARIMA. The models were used to fore-cast the daily electricity rates of distribution utilities per region in Luzon for years 2017-2019.
The graph of electricity demand per region in Luzon shows a stabilized trend throughout the whole two years with minimal fluctuations. It can be seen that there are sudden peaks in the demand of each region, mainly cause by the temperature rise and El Nino which occurred in 2015.

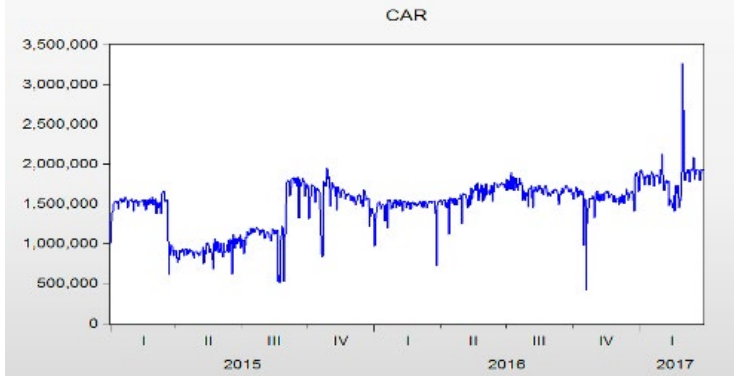

Figure 1. Electricity demand in CAR.

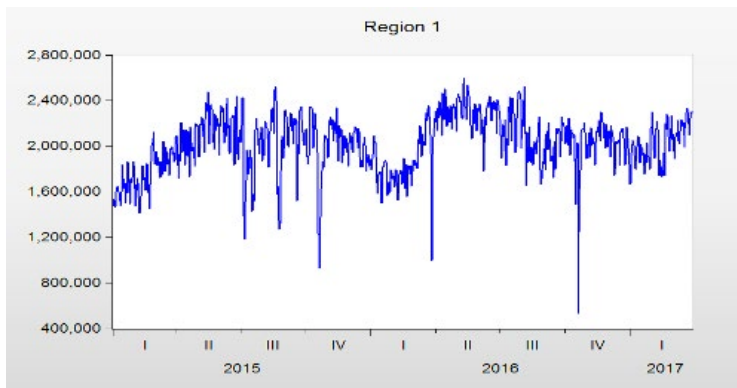

Figure 2. Electricity demand in Region 1.

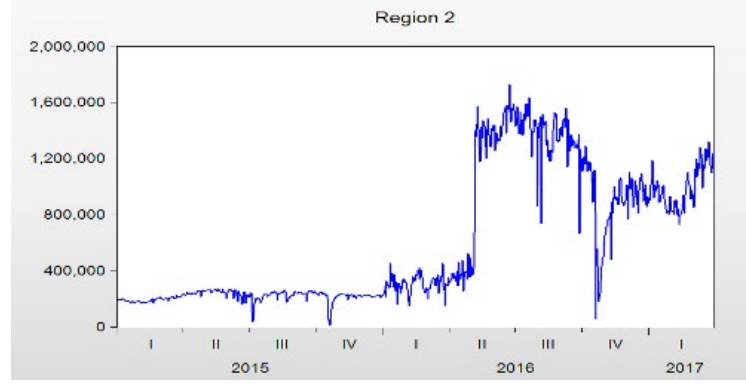

Figure 3. Electricity demand in Region 2.

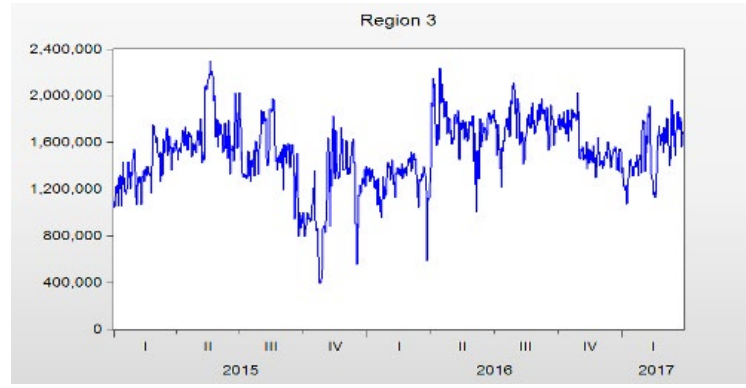

Figure 4. Electricity demand in Region 3. 


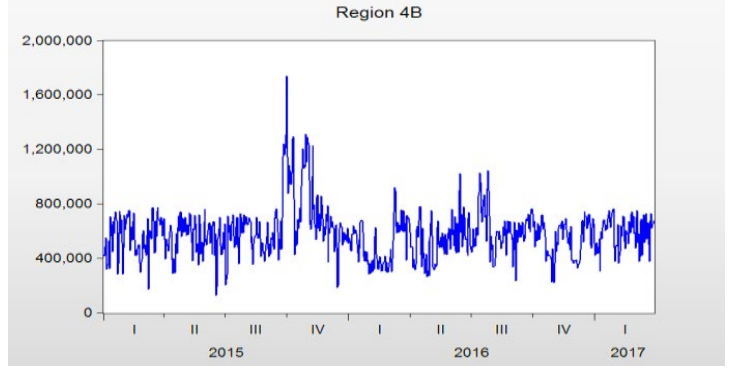

Figure 5. Electricity demand in Region 4B.

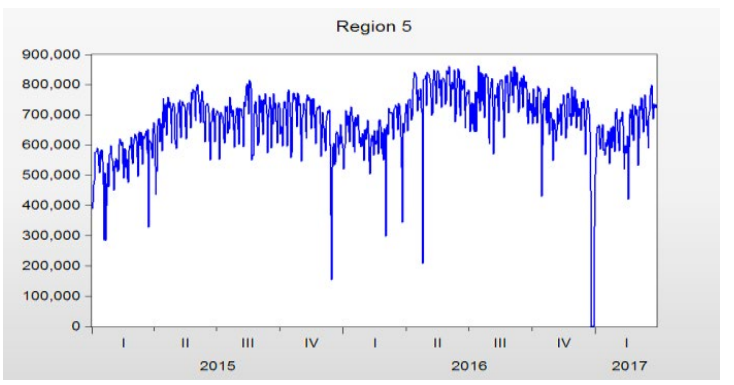

Figure 6. Electricity demand in Region 5.

Figures 1 and 2 showed a stabilized demand of electricity in CAR and Region 1. From the graph of Region 2 as shown in Figure 3, the demand of electricity is low in 2015 and it suddenly rises in 2016 due to modernization of the region. From Regions 3, 4 to 5 as shown in Figures 4, 5 and 6 , they revealed that the demand drops to almost zero during every late quarter 4 . This is because of several calamities that made the distributor shut down for a few days.

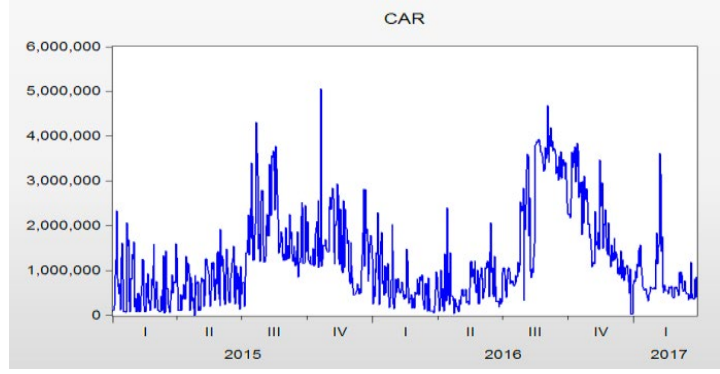

Figure 7. Electricity supply in CAR.

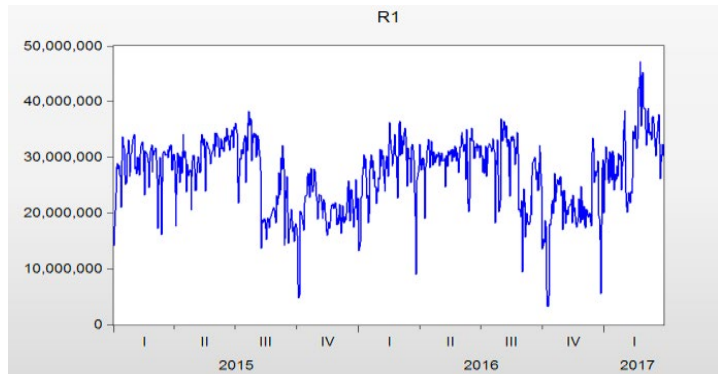

Figure 8. Electricity supply in Region 1.

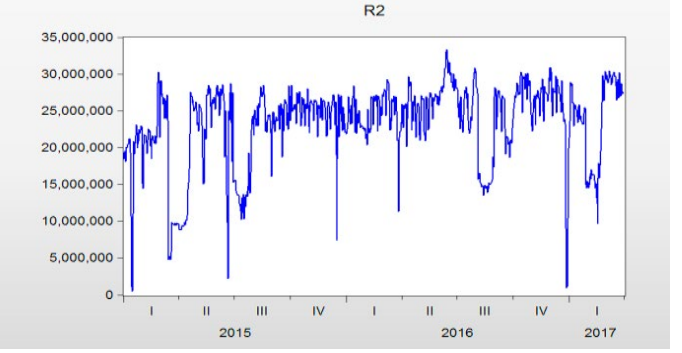

Figure 9. Electricity supply in Region 2.

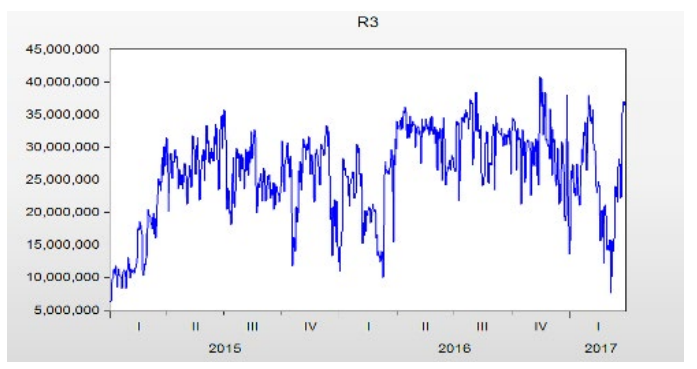

Figure 10. Electricity supply in Region 3.

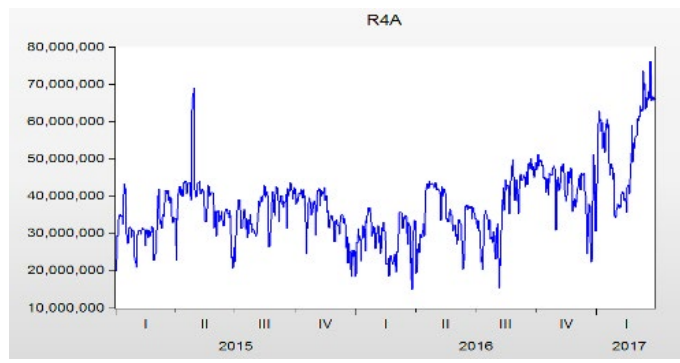

Figure 11. Electricity supply in Region 4A.

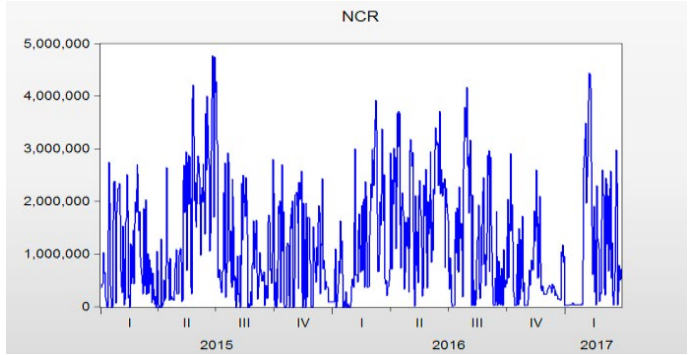

Figure 12. Electricity supply in NCR.

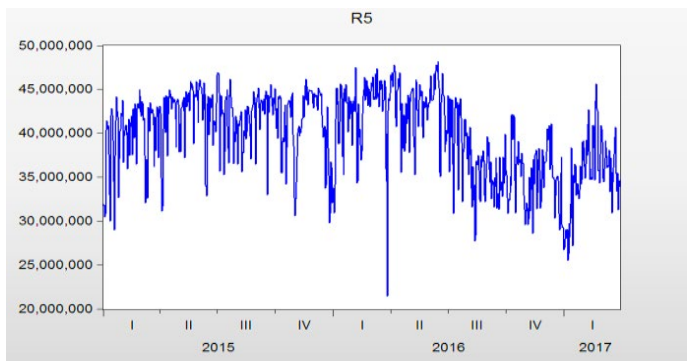

Figure 13. Electricity supply in Region 5. 
Figures 7 to 13 show the electricity supply in Luzon revealing a stabilized trend per region. The fluctuations are caused by the seasonal changes in the Philippines that affects as well as the demand for electricity especially during cold months. For Region 4A as shown in Figure 11, the supply goes higher at the end of 2016 since there were newly-constructed power plants.

To find the best model for the electric demand and supply, the data series needs to be stationary. Using unit root test, it was shown that the data series were stationary at first difference. The correlogram shows lags with significant spikes. These lags are used for formulating possible combinations of AR and MA terms to be used for the ARIMA model. The one with the lowest value of errors among the candidate models will be the best model for the time series.

Table 1. Models for electricity demand

\begin{tabular}{|c|c|c|c|c|c|c|c|}
\hline 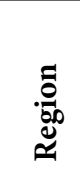 & 胥 & 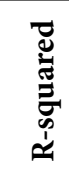 & $\frac{u}{4}$ & 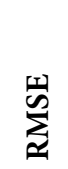 & $\sum^{\mathscr{n}}$ & $\stackrel{5}{\sum}$ & $\stackrel{U}{U}$ \\
\hline CAR & $1,1,1$ & 0.99 & 5.12 & 3.11 & 9.69 & $1.28 \mathrm{e}-4$ & $1.02 \mathrm{e}-6$ \\
\hline 1 & $1,1,1$ & 0.99 & 5.55 & 3.87 & 14.96 & $1.45 \mathrm{e}-4$ & $9.48 \mathrm{e}-6$ \\
\hline 2 & $1,1,1$ & 0.99 & 5.29 & 3.39 & 11.50 & $3.74 \mathrm{e}-4$ & $2.17 \mathrm{e}-6$ \\
\hline 3 & $1,1,1$ & 0.99 & 5.19 & 3.22 & 10.38 & $1.4 \mathrm{e}-4$ & $1.04-6$ \\
\hline $4 B$ & $1,1,1$ & 0.99 & 5.02 & 2.96 & 8.77 & $4.15 \mathrm{e}-4$ & $2.43-6$ \\
\hline 5 & $1,1,1$ & 0.99 & 3.91 & 1.70 & 2.89 & $1.86 \mathrm{e}-4$ & $1.23 \mathrm{e}-6$ \\
\hline
\end{tabular}

Table 1 shows the best model for the electricity demands per region in Luzon is ARIMA $(1,1,1$,) with one AR term, differenced once and one MA term.

Table 2. Models for electricity supply

\begin{tabular}{|c|c|c|c|c|c|c|c|}
\hline 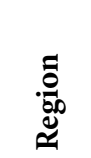 & 胥 & 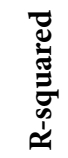 & $\frac{\cup}{4}$ & 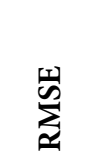 & $\sum^{\infty}$ & $\sum_{\Sigma}^{L}$ & $\underset{\sigma}{U}$ \\
\hline CAR & $2,1,2$ & 0.99 & 8.16 & 14.25 & 203.04 & $1.93 \mathrm{e}-3$ & $4.5 e-6$ \\
\hline 1 & $3,1,1$ & 0.99 & 11.55 & 77.61 & 6023.02 & $2.54 \mathrm{e}-3$ & $1.4 \mathrm{e}-6$ \\
\hline 2 & $3,1,2$ & 0.99 & 10.91 & 56.32 & 3171.84 & $2.42 \mathrm{e}-3$ & $1.2 \mathrm{e}-6$ \\
\hline 3 & $1,1,1$ & 0.99 & 10.89 & 55.76 & 3109.45 & $1.64 \mathrm{e}-3$ & $1.0 \mathrm{e}-6$ \\
\hline $4 \mathrm{~A}$ & $2,1,1$ & 0.99 & 11.41 & 72.48 & 5253.62 & $1.41 \mathrm{e}-3$ & $9.3 e-7$ \\
\hline 5 & $2,1,1$ & 0.99 & 11.13 & 63.04 & 3974.47 & $1.19 \mathrm{e}-3$ & $7.9 \mathrm{e}-7$ \\
\hline NCR & $3,1,1$ & 0.99 & 8.66 & 18.23 & 332.17 & $6.92 \mathrm{e}-3$ & $5.8 \mathrm{e}-6$ \\
\hline
\end{tabular}

Table 2 shows the best model for ARIMA model for the electricity supply per region in Luzon. CAR electricity demand was modeled ARIMA $(2,1,2)$ with two AR term, differenced once and 2 MA term. Region 1 and NCR both have modeled ARIMA $(3,1,1)$ with three AR term, difference once and one MA term. Also, region 2 was modeled ARIMA $(3,1,2)$ with three AR term, differenced once and two MA term. Moreover, region $4 \mathrm{~A}$ and 5 were modeled ARIMA $(2,1,1)$ with two AR term, differenced once and one MA term.

The following graphs show the electric demand of distribution utilities per region in Luzon and its forecasted values for the next two years. The gray line was the actual values and the red line was the forecasted values.

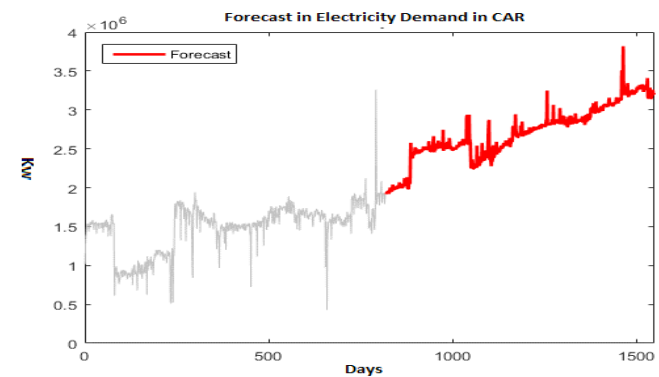

Figure 14. Forecast in electricity demand in CAR.

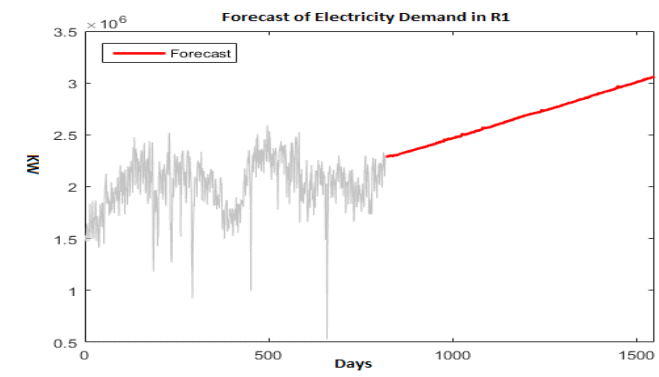

Figure 15. Forecast in electricity demand in Region 1.

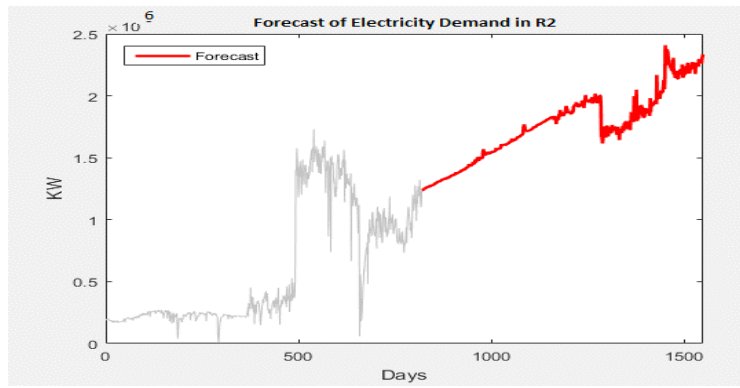

Figure 16. Forecast in electricity demand in Region 2. 


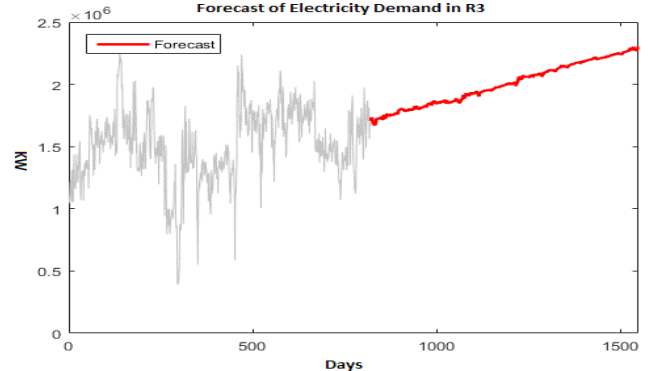

Figure 17. Forecast in electricity demand in Region 3.

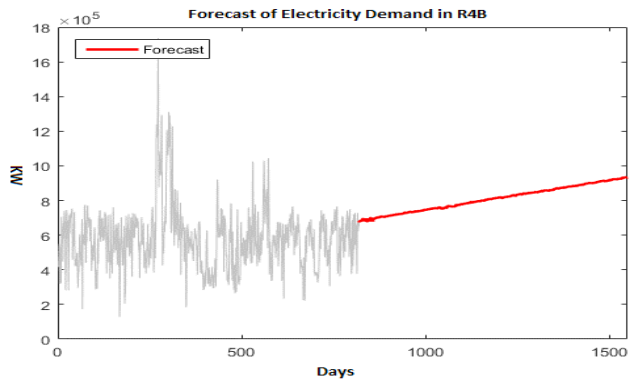

Figure 18. Forecast in electricity demand in Region 4B.

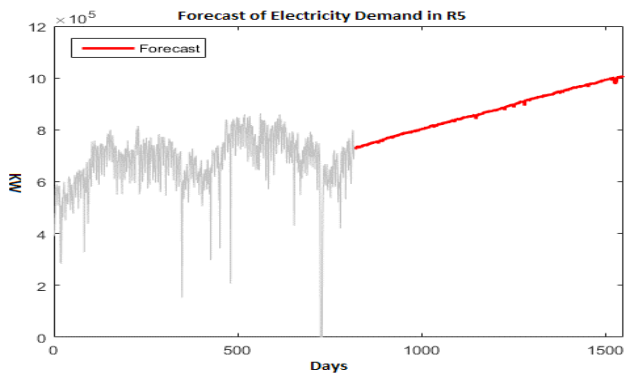

Figure 19. Forecast in electricity demand in Region 5.

According to the forecasts from Figures 14 to 19, all distribution utilities in Luzon will have an increase for electric demand. The expanding of population and modernization can be the cause of the continuous increase in the demand of electricity in Luzon.

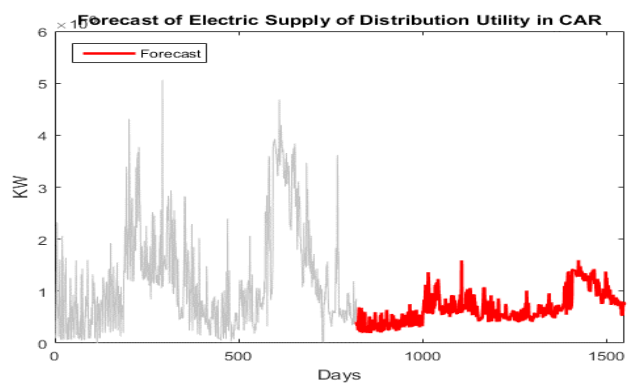

Figure 20. Forecast in electricity supply in CAR.

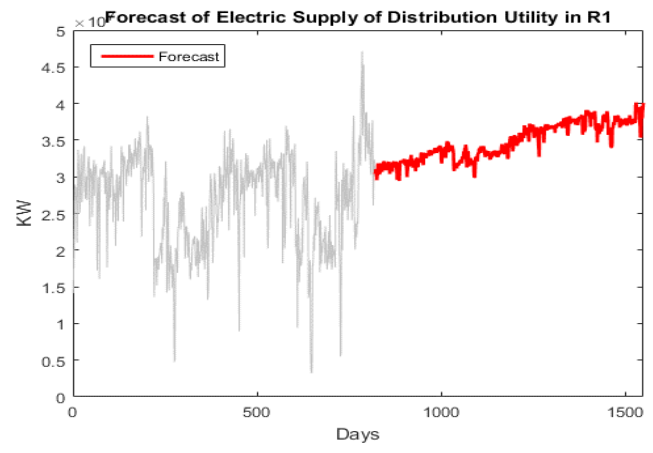

Figure 21. Forecast in electricity supply in Region 1.

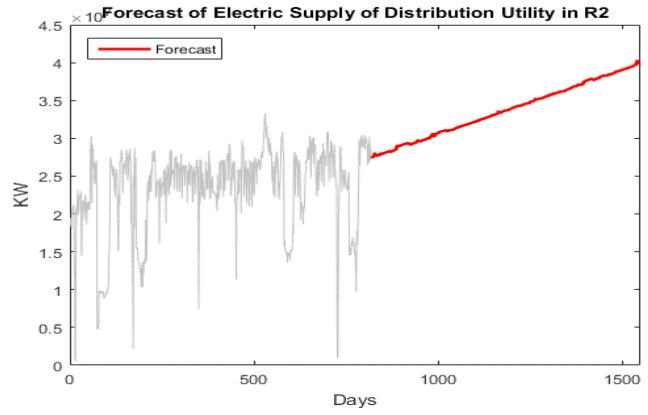

Figure 22. Forecast in electricity supply in Region 2.

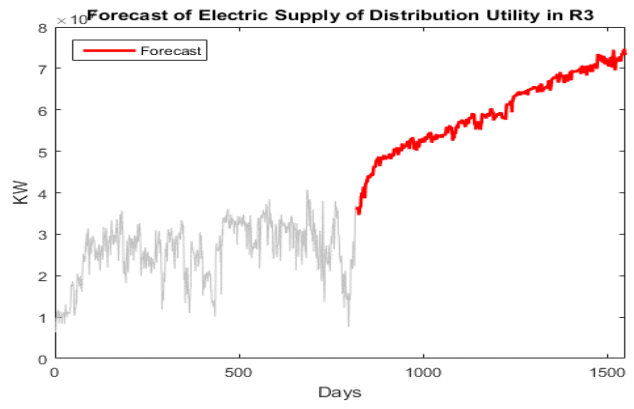

Figure 23. Forecast in electricity supply in Region 3.

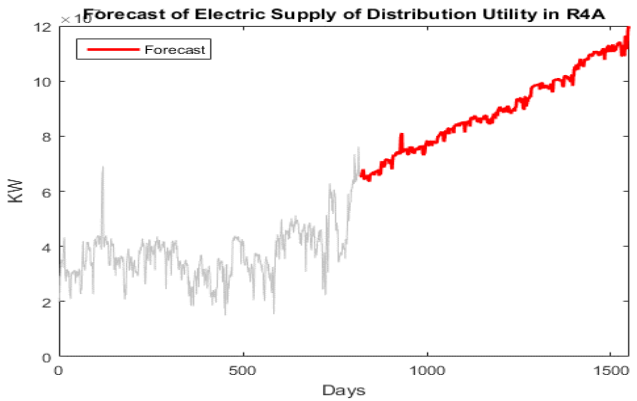

Figure 24. Forecast in electricity supply in Region 4A. 


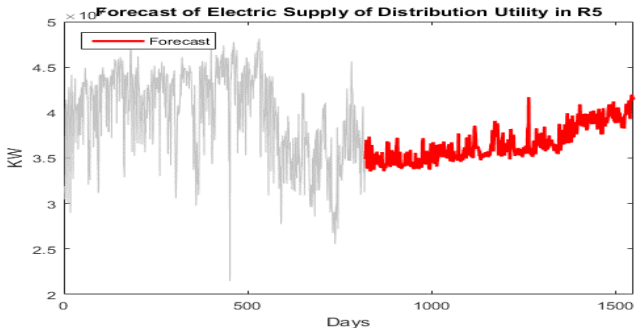

Figure 25. Forecast in electricity supply in Region 5.

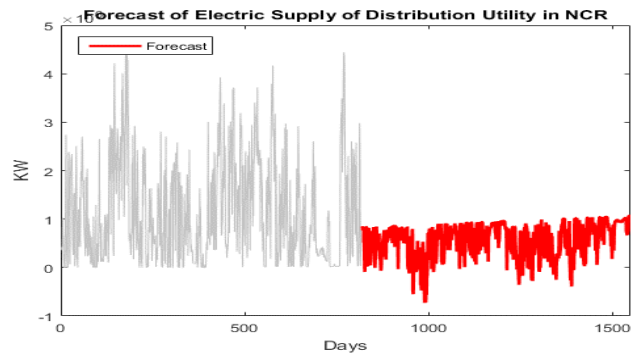

Figure 26. Forecast in electricity supply in NCR.

Figures 20 to 26 show the forecasted electricity supply for each region in Luzon. It can be seen that electricity supply from this region is gradually increasing. However, forecasted electricity supply to CAR, Region 5 and NCR as shown in Figures 20, 25 and 26 respectively, seems to be stationary.

Using the paired t-test, the researchers can determine if there is a significant difference between the actual values and forecasted values of the daily electric demand and supply of distribution utilities of each region in Luzon.

Table 3. Paired T-test for electricity demand

\begin{tabular}{|l|l|l|l|}
\hline Region & T-statistic & Decision & Interpretation \\
\hline CAR & 0.8655 & Accept Ho & Not Significant \\
\hline $\mathbf{1}$ & 0.8565 & Accept Ho & Not Significant \\
\hline $\mathbf{2}$ & 0.8055 & Accept Ho & Not Significant \\
\hline $\mathbf{3}$ & 0.7010 & Accept Ho & Not Significant \\
\hline $\mathbf{4}$ & 0.9943 & Accept Ho & Not Significant \\
\hline $\mathbf{5}$ & 0.9012 & Accept Ho & Not Significant \\
\hline
\end{tabular}

Table 3 shows the significant difference between the actual electricity demand and forecasted electricity demand. With a level of significance of 0.01 , it was found out that there is no significant difference between the actual and forecasted values of electricity demand in CAR and Regions 1 to 5 .
Table 4. Paired T-test for electricity supply

\begin{tabular}{|l|l|l|l|}
\hline Region & T-statistic & Decision & Interpretation \\
\hline CAR & 0.8761 & Accept Ho & Not Significant \\
\hline NCR & 0.9477 & Accept Ho & Not Significant \\
\hline $\mathbf{1}$ & 0.8624 & Accept Ho & Not Significant \\
\hline $\mathbf{2}$ & 0.8345 & Accept Ho & Not Significant \\
\hline $\mathbf{3}$ & 0.9125 & Accept Ho & Not Significant \\
\hline $\mathbf{4}$ & 0.9556 & Accept Ho & Not Significant \\
\hline $\mathbf{5}$ & 0.9361 & Accept Ho & Not Significant \\
\hline
\end{tabular}

Table 4 shows the significant difference between the actual electricity supply and forecasted electricity supply. With a level of significance of 0.01 , it was found out that there is no significant difference between the actual and forecasted values of electricity supply in CAR, NCR and Regions 1 to 5 .

\section{Conclusions}

This study aims to find the best ARIMA model to forecast the electric demand and supply of different distribution utilities in each region of Luzon for years 2017-2019. After analyzing the data series, the following ARIMA models were made: ARIMA $(1,1,1)$ for electric demand of CAR, Region 1, Region 2, Region 3, Region 4B and Region 5 and for electric supply, ARIMA $(2,1,2)$ for CAR, ARIMA $(3,1,1)$ for NCR and Region 1, ARIMA $(3,1,2)$ for Region 2, ARIMA $(1,1,1)$ for Region 3 and ARIMA $(2,1,1)$ for Region $4 \mathrm{~A}$ and Region 5 . The forecasted demand of electricity of distribution utilities in every region for years 2017 to 2019 will continue to increase. The forecasted electric supply of distribution utilities in every region for years 2017 to 2019 will go through an increase and decrease from time to time but still trend upwards. It is also being shown that there is no significant difference between the actual and forecasted values.

\section{References}

1. Tejada J. Forecasting prices in electricity markets. 2011. H. Poor. An introduction to signal detection and estimation. New York: Springer-Verlag; ch. 4, 1985. crossref

2. Basilio R. A guide to the Philippines. 2013. crossref

3. Bastian J, et al. Forecasting energy prices in a Competitive Market. 2009; 12:40-5. 
4. Zhang $\mathrm{H}$, et al. Optimal bidding strategies for wind power producers in the day-ahead electricity market. Energies 2012. 2012; 5:4804-23. crossref

5. Schneider S. Power spot price models with negative prices. J. Energy Mark. 2012; 4:77-102. crossref
6. Contreras J, et al. ARIMA models to predict nextday electricity prices. IEEE Trans Power System. 2011; 18(3):1014-20. crossref

7. Mandal P. et al. A new recursive neural network algorithm to forecast electricity price for PJM day-ahead market. J Energy Res. 2010; 34:507-22. crossref 